\title{
CARACTERÍSTICAS EPIDEMIOLÓGICAS DOS ACIDENTES NA INFÂNCIA
}

Carmen Vieira de Sousa Unglert*

Arnaldo Augusto Franco de Siqueira*

Gizélia Andrade Carvalho**

\begin{abstract}
UNGLERT, C.V. de S. et al. Características epidemiológicas dos acidentes na infância. Rev. Saúde públ., S. Paulo, 21:234-45, 1987.
\end{abstract}

RESUMO: Foram estudadas as características epidemiológicas dos acidentes na infância, através da aplicação de questionário. Foram levantados os acidentes ocorridos num período de 2 anos em crianças de famílias que freqüentavam dois postos de assistência médica de bairros situados na periferia da cidade de São Paulo, SP, Brasil. Foram entrevistadas 388 famílias, com um total de 1.036 crianças de 0 a 12 anos. Das familias, 289 não referiram qualquer acidente nas crianças nos dois anos anteriores. Em 99 famílias foi referido pelo menos 1 acidente, sendo registrado um total de 122 . Os tipos de acidentes mais freqüentes foram as quedas $(54,1 \%)$, ferimentos causados por objetos cortantes ou penetrantes $(13,1 \%)$ e mordeduras por animais $(9,8 \%)$. As lesões mais freqüentes foram os cortes $(26,2 \%)$, contusões $(24,6 \%)$ e escoriações $(17,2 \%)$. A maior incidência de acidentes ocorreu em meninos de 5 a 9 anos seguido de meninos de 10 a 12 anos. A recuperação foi total em $88,5 \%$ dos casos, havendo $9,8 \%$ de casos com recuperação parcial, com sinais, 1 caso de recuperação parcial, com limitações, e um óbito. Em $91 \%$ dos casos não houve necessidade de internação, mas em $32,0 \%$ dos casos foram necessários 15 dias ou mais para que a recuperação se desse. O coeficiente de mortalidade encontrado foi de 114,9 obitos para cem mil crianças menores de 12 anos por ano e a letalidade foi de 8,2 óbitos por mil acidentes. O estudo permitiu acrescentar série de dados complementares que facilitam a caracterização epidemiológica dos acidentes na infância.

UNITERMOS: Criança. Acidentes. Epidemiologia. Mortalidade. Morbidade.

\section{INTRODUÇÃO}

Os acidentes constituem um importante fator na estrutura da morbi-mortalidade na infância. Nos países desenvolvidos surgem como a principal causa de óbitos de crianças maiores de um ano. Dershewitz e Christophersen ${ }^{3}$ referem que, nos Estados Unidos, a cada ano, cerca de 3.000 crianças menores de quatorze anos morrem devido a acidentes domésticos. As queimaduras são a principal causa de óbito, ainda segundo Dershewitz e Christophersen ${ }^{3}$, seguindo-se a asfixia e o afogamento. Brannick e Kirke ${ }^{1}$, que estudaram os acidentes na infância, na Irlanda, durante dez anos, verificaram que o coeficiente de mortalidade específico foi de 16,1 por 100.000 habitantes, sendo que o número de crianças do sexo masculino que morreram foi o dobro do número de crianças do sexo feminino. As principais causas detectadas por aqueles autores foram o afogamento, as queimaduras e as quedas, em crianças de um a 4 anos, e os acidentes de trânsito nas crianças de faixas etárias maiores.

Sibert ${ }^{13}$ (1983) e Sibert e col. ${ }^{14}$ (1981), em estudos realizados na Inglaterra, demonstraram que cerca de uma em cada 5 crianças, residentes em uma determinada área, necessitava de atendimento hospitalar, por acidente, no período de um ano. A causa mais freqüente de acidentes referida por aqueles autores foram as quedas principalmente as de escadas. As mordeduras por cão também foram freqüentes assim como os acidentes com bicicletas.

Koblenz ${ }^{7}$, num estudo efetuado em 1975, em Paris, estabeleceu as características epidemiológicas dos acidentes que resultaram em internação no serviço de cirurgia infantil de um determinado hospital. Verificou esse autor que, da totalidade dos acidentes, $47 \%$ eram fraturas e $20 \%$ queimaduras. Os principais agentes encontrados foram os elevadores e as escadas, bem como os produtos de limpeza doméstica. Manciaux e Jeanneret ${ }^{8}$, em estudo também realizado em Paris, em 1983, chamam a atenção no sentido de que o conhecimento epidemiológico dos acidentes na infância ainda é incompleto e parcial, sendo que o que predomina são as estatísticas de mortalidade ou casos que tenham ne-

\footnotetext{
* Departamento de Saúde Materno-Infantil da Faculdade de Saúde Pública da Universidade de São Paulo - Av. Dr. Arnaldo, 715 - 01255 - São Paulo, SP - Brasil.

** Secretaria de Higiene e Saúde da Prefeitura do Município de São Paulo - Posto de Assistência Médica de Vila Santa Catarina - Rua Belmiro Zaneti Esteves, 181 - 01000 - São Paulo, SP - Brasii.
} 
cessidade de hospitalização. Faltam, assim, dados relativos à morbidade.

Fortin ${ }^{4}$, em 1984, estabeleceu uma análise sobre os acidentes ocorridos na pré-escola, em Grenoble, França, com crianças de 2 a 6 anos. Nesse caso, teve a oportunidade de estudar aspectos ligados inclusive aos acidentes mais leves, que não chegam a necessitar de cuidados médicos. Verificou, assim, que a lesão mais freqüente era a equimose, seguida de corte, que a maioria das lesões ocorria na cabeça e que $46 \%$ dos acidentes ocorriam durante o recreio. Um outro trabalho que se preocupou com as características epidemiológicas e sociais dos acidentes na infância foi o desenvolvido por Hoz e Hernandes ${ }^{6}$, em Cuba, em 1984, quando estudaram a relação dos acidentes com alguns fatores de natureza social, como composição do núcleo familiar, características da moradia e nível de escolaridade dos pais de crianças acidentadas.

Em nosso meio, poucos são os trabalhos que têm abordado o problema dos acidentes na infância. Wilson ${ }^{16}$ efetuou um estudo pioneiro, em 1966, analisando as características dos acidentes domésticos, em todas as idades, de residentes no subdistrito de Vila Madalena, Município de São Paulo. Observou que os principais acidentes foram queimaduras, choques e cortes e que os mesmos ocorriam principalmente na cozinha ou no quintal. Mello Jorge ${ }^{9}$, em 1979, estudou a mortalidade por causas violentas no Município de São Paulo, tendo verificado que, em crianças de 0 a 4 anos, a principal causa de óbito foi a queda, seguida pelo atropelamento. Já nas faixas etárias maiores, até 14 anos, a principal causa foi o atropelamento e a segunda o afogamento. Rodrigues e col. ${ }^{10}$, em 1980 , estabeleceram o levantamento das cinco principais causas de óbito, no Estado do Rio de Janeiro, em todas as idades, mostrando a relevância dos acidentes na faixa etária superior a 4 anos de idade, e recomendando uma ficha de atendimento de acidentes padronizada de forma a uniformizar critérios e condutas para melhor avaliação futura.

Schvartsmann ${ }^{11,12}$ tem se dedicado ao estudo das intoxicações na infância, dando ênfase aos produtos químicos de uso domiciliar e às plantas venenosas.

Observa-se, assim, que os estudiosos da área vêm concentrando seus trabalhos principalmente na questão da mortalidade por acidentes, sendo que há, ainda, um longo caminho a percorrer, no que se refere aos aspectos relativos à morbidade. E mesmo com relação à mortalidade, ainda pouco se explorou as características epidemiológicas de tais eventos. Pretende-se, dessa forma, com o presente estudo, contribuir para ampliar o conhecimento sobre as características epidemiológicas da morbi-mortalidade por acidentes em crianças, através da análise dos elementos que intervêm nos mesmos, vinculando-os ao contexto social no qual se inserem. Ao se pretender desenvolver tal análise a nível de domicílio, objetiva-se conhecer não somente os eventos que culminaram em óbito ou internação, mas também as circunstâncias que cercam os acidentes de menor gravidade, para se estabelecer um quadro mais abrangente da situação atual e, com isso, abrir uma perspectiva de prevenção de acidentes com base nas necessidades detec- tadas. Programas e medidas específicas de prevenção de acidentes, que se mostraram como de grande eficiência, como o descrito por Spiegel e Lindaman ${ }^{15}$, desenvolvido em Nova York, denominado "Crianças não podem voar", ou ainda, como o relatado por Clarke e Walton ${ }^{2}$, nos Estados Unidos, relativo à introdução de tampas com sistema de segurança, nos frascos de aspirina, obtiveram sucesso provavelmente porque foram baseados em necessidades detectadas a partir da realidade daquele país. Certamente algumas medidas poderão ser adaptadas e agilizadas em nosso meio. Contudo, considerase imprescindível o melhor conhecimento de nossas necessidades, para o estabelecimento de programas e medidas de prevenção adequados às mesmas.

\section{MATERIAL E MÉTODOS}

O presente estudo foi realizado em dois postos de assistência médica (PAM) da Prefeitura do Município de São Paulo. Um deles, o PAM Jardim São Luis, está localizado no sub-distrito de Paz de Santo Amaro, e o outro, o PAM Dona Maria Antonieta de Barros, está situado no sub-distrito de Paz de Capela do Socorro.

O instrumento utilizado foi um questionário, aplicado em mães de crianças que passaram por consulta médica de controle ou patologia nas unidades referidas. Foi estabelecida uma amostragem sistemática não estratificada, sendo os questionários aplicados pelos médicos consultantes. $\mathrm{O}$ questionário foi montado com o objetivo de estabelecer um levantamento de variáveis socioeconômicas da família, além de dados específicos relativos à ocorrência de acidentes em todas as crianças da família. O período de aplicação foi de seis meses, de fevereiro a junho de 1984, sendo estudados todos os acidentes ocorridos nos anos de 1982 e 1983 com crianças de 0 a 12 anos pertencentes às famílias em estudo e referidos pela mãe. Considerou-se o conceito de acidente como foi relatado pelas mães. A seguir, estabeleceu-se a análise dos dados coletados, procurando identificar as diferentes características observadas bem como as medidas passíveis de aplicação às diferentes situações.

Neste estudo será feita uma caracterização geral dos principais aspectos relacionados à ocorrência de acidentes nessas crianças, enfatizando-se os aspectos relativos à incidência e morbidade.

Para o cálculo do coeficiente de incidência e mortalidade por acidentes, levou-se em conta o tempo de exposição das crianças incluídas no estudo, uma vez que para as crianças menores de 2 anos esse tempo foi menor.

A classificação de ocupação dos pais aqui utilizada foi a de Gouveia ${ }^{5}$.

\section{RESULTADOS}

Foram incluídos para estudo os dados relativos a 388 entrevistas feitas quase sempre com as mães das crianças atendidas nos dois postos de saúde (PAMs), num total de 1.036 crianças. Algumas das entrevistas foram realizadas com avós ou irmãos mais velhos, das crianças; no entanto, sempre se tratavam de pessoas residen- 
tes no mesmo domicílio.

Dessas famílias, 289 não referiram qualquer acidente nos dois anos anteriores, nas crianças. Em 99 famílias as mães referiram pelo menos um acidente com alguma das crianças no período considerado. Assim é que foram registrados, nessas 99 famílias, 122 acidentes.

As Tabelas 1 a 7 referem-se ao total de famílias entrevistadas em dois grupos, "com" e "sem" acidentes.

A Tabela 1 mostrou o tipo de família. Verifica-se que a maioria das famílias, tenham ou não relatado acidentes, são compostas de pai, mãe e filhos, ou pai, mãe, filhos e outros, chegando a mais de $90 \%$ do total de famílias.

Apenas duas famílias não contavam com a presença da mãe; 7 a $9 \%$ das famílias não contavam com a presença do pai. Importante é ressaltar a grande semelhança entre famílias que relataram ou não a ocorrência de acidentes.

Ainda em relação à caracterização das famílias, a Tabela 2 mostrou a distribuição etária dos pais das crianças.
No grupo de famílias "com acidentes", tanto no caso dos pais como das mães das crianças, houve menor proporção de pais em faixas etárias mais velhas, ou seja, $38,3 \%$ dos pais e $25,3 \%$ das mães "com acidentes" tinham 35 anos e mais, ao passo que apenas $27 \%$ dos pais e $16,3 \%$ das mães "sem acidentes" tinham 35 anos e mais. Inversamente, apenas $7,1 \%$ dos pais e $14,1 \%$ das mães "com acidentes" tinham menos de 25 anos; para o grupo "sem acidentes" esses valores foram de $15,2 \%$ para os pais e $29 \%$ para as mães.

Assim, os pais das crianças do grupo sem acidentes eram, em geral, mais jovens.

Quanto à escolaridade dos pais, a Tabela 3 mostrou que as mães têm menor escolaridade que os pais, e que a grande maioria (mais de $75 \%$ de pais e de mães) tem, no máximo, o primeiro grau incompleto. Alèm disso, a Tabela mostrou que a distribuição percentual pelas classes de escolaridade foi muito semelhante entre pais dos grupos "com acidentes" e "sem acidentes", o mesmo tendo ocorrido com as mães.

Em relação à ocupação, a Tabela 4 mostrou uma distribuição em tudo semelhante ao já descrito para a escolaridade, com diferenças entre pais e mães, mas com

\section{TABELA 1}

Tipo de família das crianças e ocorrência de acidentes no período de 1982 - 1984 .

\begin{tabular}{lrrrr}
\hline $\begin{array}{l}\text { Tipo de } \\
\text { família }\end{array}$ & No. Com acidente & \multicolumn{2}{c}{ Sem acidente } \\
\hline Pai, mãe, filhos & 78 & 78,8 & 232 & \multicolumn{1}{c}{ No } \\
Pai e filhos & - & - & 1 & 80,3 \\
Mãe e filhos & 2 & 2,0 & 14 & 0,3 \\
Pai, mãe, filhos e outros & 14 & 14,1 & 28 & 4,9 \\
Mãe, filhos e outros & 5 & 5,1 & 13 & 9,7 \\
Filhos e outros & - & - & 1 & 4,5 \\
\hline Total & 99 & 100,0 & 289 & 0,3 \\
\hline
\end{tabular}

TABELA 2

Idade dos pais das crianças e ocorrência de acidentes no período de 1982 - 1984

\begin{tabular}{|c|c|c|c|c|c|c|c|c|c|}
\hline \multicolumn{2}{|c|}{ Pais } & \multicolumn{4}{|c|}{ Pai } & \multicolumn{4}{|c|}{ Mãe } \\
\hline \multirow{2}{*}{$\begin{array}{l}\text { Idade dos } \\
\text { pais (anos) }\end{array}$} & \multirow{2}{*}{ Acidentes } & \multicolumn{2}{|c|}{ Com acidente } & \multicolumn{2}{|c|}{ Sem acidente } & \multicolumn{2}{|c|}{ Com acidente } & \multicolumn{2}{|c|}{ Sem acidente } \\
\hline & & No & $\%$ & N. & $\%$ & No. & $\%$ & No & $\%$ \\
\hline 15 a 19 & & - & - & 2 & 0,7 & 2 & 2,0 & 20 & 6,9 \\
\hline 20 a 24 & & 7 & 7,1 & 42 & 14,5 & 12 & 12,1 & 64 & 22,1 \\
\hline 25 a 29 & & 18 & 18,2 & 74 & 25,6 & 39 & 39,4 & 87 & 30,1 \\
\hline 30 a 34 & & 28 & 28,3 & 57 & 19,7 & 21 & 21,2 & 69 & 23,9 \\
\hline 35 a 39 & & 21 & 21,2 & 52 & 18,0 & 18 & 18,2 & 25 & 8,7 \\
\hline 40 a 49 & & 14 & 14,1 & 20 & 6,9 & 7 & 7,1 & 19 & 6,6 \\
\hline 50 a 59 & & 2 & 2,0 & 8 & 2,8 & - & - & 2 & 0,7 \\
\hline $60 e+$ & & 1 & 1,0 & 1 & 0,4 & - & - & 1 & 0,3 \\
\hline Não se aplica & & 7 & 7,1 & 28 & 9,7 & - & - & 2 & 0,7 \\
\hline Ignorado & & 1 & 1,0 & 5 & 1,7 & - & 一 & 一 & - \\
\hline Total & & 99 & 100,0 & 289 & 100,0 & 99 & 100,0 & 289 & 100,0 \\
\hline
\end{tabular}


TABELA 3

Escolaridade do pai e da mãe das crianças e ocorrência de acidentes no período de 1982 - 1984

\begin{tabular}{|c|c|c|c|c|c|c|c|c|c|}
\hline \multirow{3}{*}{$\begin{array}{ll} & \text { Pais } \\
\text { Escolaridade } & \end{array}$} & & \multicolumn{4}{|c|}{ Pai } & \multicolumn{4}{|c|}{ Mãe } \\
\hline & \multirow[b]{2}{*}{ Acidentes } & \multicolumn{2}{|c|}{ Com acidente } & \multicolumn{2}{|c|}{ Sem acidente } & \multicolumn{2}{|c|}{ Com acidente } & \multicolumn{2}{|c|}{ Sem acidente } \\
\hline & & No & $\%$ & No & $\%$ & No & $\%$ & № & $\%$ \\
\hline Analfabeto & & 9 & 9,1 & 29 & 10,0 & 22 & 22,2 & 39 & 13,5 \\
\hline Alfabetizado & & 10 & 10,1 & 28 & 9,7 & 6 & 6,1 & 22 & 7,6 \\
\hline $1 \%$ grau incompleto & & 63 & 63,6 & 174 & 60,2 & 54 & 54,5 & 130 & 45,0 \\
\hline 1 . grau completo & & 8 & 8,1 & 14 & 4,8 & 5 & 5,1 & 8 & 2,7 \\
\hline $2{ }^{\circ}$ grau incompleto & & - & & - & 0,7 & - & - & - & - \\
\hline 2 . grau completo & & - & & - & - & - & - & - & 一 \\
\hline Superior incompleto & & - & & - & - & - & - & - & 一 \\
\hline Superior completo & & - & & 1 & 0,4 & 1 & 1,0 & - & - \\
\hline Não se aplica & & 7 & 7,1 & 28 & 9,7 & - & - & 2 & 0,7 \\
\hline Ignorado & & 2 & 2,0 & 13 & 4,5 & 11 & 11,1 & 88 & 30,5 \\
\hline Total & & 99 & 100,0 & 289 & 100,0 & 99 & 100,0 & 289 & 100,0 \\
\hline
\end{tabular}

grande semelhança entre pais e entre mães. Vale ressaltar que mais de $2 / 3$ das mães preferiram trabalhar exclusivamente nos afazeres domésticos.

Quanto ao tempo de residência em São Paulo (Tabela 5), quase $50 \%$ de todos os subgrupos, com ou sem acidentes, pais ou mães, residiam no município há mais de 10 anos; pequena proporção (pouco mais de $2 \%$ ) residiam há menos de um ano; isso se verificou tanto para pais como para mães. Em todos os subgrupos a distribuição percentual foi muito semelhante o que permite dizer que, na amostra em estudo, o tempo de residência provavelmente não teve importância como fator associado a acidentes em crianças.

Quanto ao número de filhos, 7\% das famílias com acidentes tinham um filho, ao passo que $30,1 \%$ das sem acidentes tinham apenas um filho; do grupo "com acidentes", $42,4 \%$ das famílias tinham 4 filhos ou mais; já no grupo "sem acidentes" apenas $23,2 \%$ delas tinham 4 filhos ou mais (Tabela 6).

Quanto ao número médio de filhos por família, as famílias "com acidentes" tinham em média 3,6 filhos e as "sem acidentes" tinham em média 2,6 .

Já quanto à idade dos filhos, também se verificou que os das famílias "sem acidentes" eram mais jovens que os das com acidentes.

Quando se procurou verificar quem cuida das crianças, em 78,8\% das famílias sem acidentes, foi referido ser a mãe quem cuidava delas. Em cerca de $10 \%$ dos casos eram os avós ou irmãos; em alguns casos eram vizinhos ou creches.

Tanto num como no outro grupo, pouco mais de $25 \%$ das mães referiam trabalhar fora.

Do que foi visto até aqui, pode-se afirmar que, na população estudada houve muitas semelhanças entre as famílias com e sem acidentes. No entanto, cumpre ressaltar que as famílias "com acidentes" apresentavam pais e mães mais velhos, maior número de filhos e pequena proporção de filhos com idades menores. Em outras palavras, o grupo "sem acidentes" apresentava uma pro-

TABELA 4

Ocupação do pai e da mãe das crianças e ocorrência de acidentes no período de 1982 - 1984

\begin{tabular}{|c|c|c|c|c|c|c|c|c|}
\hline Pais & \multicolumn{4}{|c|}{ Pai } & \multicolumn{4}{|c|}{ mãe } \\
\hline \multirow{2}{*}{ Ocupação } & \multicolumn{2}{|c|}{ Com acidente } & \multicolumn{2}{|c|}{ Sem acidente } & \multicolumn{2}{|c|}{ Com acidente } & \multicolumn{2}{|c|}{ Sem acidente } \\
\hline & N. & $\%$ & № & $\%$ & N. & $\%$ & № & $\%$ \\
\hline Manual não especializado & 23 & 23,2 & 77 & 26,6 & 22 & 22,2 & 36 & 12,5 \\
\hline Manual especializado & 55 & 55,5 & 141 & 48,8 & 2 & 2,0 & 6 & 2,1 \\
\hline Supervisor trab. manuais & - & - & 2 & 0,7 & - & - & - & - \\
\hline Não manual rotina & 6 & 6,1 & 17 & 5,9 & 一 & - & 3 & 1,0 \\
\hline Posições baixas & & & & & & & & \\
\hline $\begin{array}{l}\text { Supervisão + pequenos } \\
\text { proprietários. }\end{array}$ & 1 & 1,0 & 6 & 2,1 & - & - & - & 一 \\
\hline Do lar & - & - & - & - & 68 & 68,7 & 206 & 71,2 \\
\hline Ignorado & 7 & 7,1 & 18 & 6,2 & 7 & 7,1 & 36 & 12,5 \\
\hline Não se aplica & 7 & 7,1 & 28 & 9,7 & 一 & - & 2 & 0,7 \\
\hline Total & 99 & 100,0 & 289 & 100,0 & 99 & 100,0 & 289 & 100,0 \\
\hline
\end{tabular}


TABELA 5

Tempo de residência do pai e da mãe das crianças e ocorrência de acidentes no período de 1982 - 1984

\begin{tabular}{|c|c|c|c|c|c|c|c|c|c|}
\hline \multicolumn{2}{|l|}{ Pais } & \multicolumn{4}{|c|}{ Pai } & \multicolumn{4}{|c|}{ Mãe } \\
\hline \multirow{2}{*}{$\begin{array}{l}\text { Tempo de } \\
\text { residência (anos) }\end{array}$} & \multirow{2}{*}{ Acidentes } & \multicolumn{2}{|c|}{ Com acidente } & \multicolumn{2}{|c|}{ Sem acidente } & \multicolumn{2}{|c|}{ Com acidente } & \multicolumn{2}{|c|}{ Sem acidente } \\
\hline & & No & $\%$ & No & $\%$ & No. & $\%$ & No & $\%$ \\
\hline 1 ano & & 2 & 2,0 & 6 & 2,1 & 2 & 2,0 & 9 & 3,1 \\
\hline 1 a 5 anos & & 14 & 14,1 & 33 & 11,4 & 14 & 14,1 & 52 & 18,0 \\
\hline 6 a 10 anos & & 22 & 22,2 & 54 & 18,7 & 25 & 25,3 & 54 & 18,7 \\
\hline Mais de 10 anos & & 47 & 47,5 & 140 & 48,4 & 48 & 48,4 & 136 & 47,0 \\
\hline Não se aplica & & 7 & 7,1 & 28 & 9,7 & 10 & 10,1 & 36 & 12,5 \\
\hline Ignorado & & 7 & 7,1 & 28 & 9,7 & - & - & 2 & 0,7 \\
\hline Total & & 99 & 100,0 & 289 & 100,0 & 99 & 100,0 & 289 & 100,0 \\
\hline
\end{tabular}

TABELA 6

Número de filhos por família das crianças e ocorrência de acidentes no período de 1982 - 1984.

\begin{tabular}{|c|c|c|c|c|}
\hline \multirow{2}{*}{ No de filhos } & \multicolumn{2}{|c|}{ Com acidente } & \multicolumn{2}{|c|}{ Sem acidente } \\
\hline & N. & $\%$ & № & $\%$ \\
\hline 1 & 7 & 7,1 & 87 & 30,1 \\
\hline 2 & 24 & 24,2 & 72 & 24,9 \\
\hline 3 & 26 & 26,3 & 63 & 21,8 \\
\hline 4 & 17 & 17,2 & 32 & 11,1 \\
\hline 5 & 8 & 8,1 & 17 & 5,9 \\
\hline 6 & 9 & 9,1 & 8 & 2,8 \\
\hline 7 & 2 & 2,0 & 4 & 1,4 \\
\hline 8 & 4 & 4,0 & 4 & 1,4 \\
\hline 9 & 1 & 1,0 & 1 & 0,3 \\
\hline 10 & - & - & 1 & 0,3 \\
\hline 11 & 1 & 1,0 & - & - \\
\hline Total & 99 & 100,0 & 289 & 100,0 \\
\hline
\end{tabular}

TABELA 7

Renda das famílias das crianças e ocorrência de acidentes no período de 1982 - 1984.

\begin{tabular}{lrrrrr}
\hline $\begin{array}{l}\text { Renda familiar } \\
\text { (em S.M.) }\end{array}$ & No & Com acidente & $\%$ & No & Sem acidente \\
\hline $0 \vdash 1$ & 9 & 9,1 & 35 & 12,1 \\
$1 \vdash 2$ & 46 & 46,5 & 157 & 54,3 \\
$2 \vdash 4$ & 37 & 37,4 & 79 & 27,3 & 5,9 \\
4 e + & 7 & 7,1 & 17 & 0,3 \\
Ignorado & - & - & 289 & 100,00 \\
\hline Total & 99 & 100,0 & & \\
\hline
\end{tabular}

S.M.: Salário mínimo

babilidade menor de acidentes devido a características da própria composição familiar. Muitas dessas famílias eram constituídas apenas de pai e mãe e uma criança lactente, menos expostas a acidentes do que, por exemplo, famílias com 2 e até 8 crianças em idade escolar.

Com relação à renda familiar, medida em salários mínimos, mais de $50 \%$ das famílias, com ou sem acidentes, ganhava menos de 2 salários mínimos; pouco mais de $5 \%$ ganhava 4 ou mais (Tabela 7 ).

A não ser, pois, por características de composição familiar que aumentassem a probabilidade de acidentes, a conclusão foi de que tanto as famílias "com acidentes" quanto as "sem acidentes" eram muito semelhan- tes entre si, talvez representativas de uma população que vive em bairro periférico de São Paulo.

O mesmo se verificou, como se verá a seguir, com relação às características da habitação, em que $90,9 \%$ das famílias com acidentes referidos e $87,2 \%$ das famílias sem menção de acidentes moravam em casas unifamiliares, ao passo que $6,1 \%$ das com acidentes e $11,8 \%$ sem acidentes moravam em habitaçãoes coletivas.

Quanto ao número de cômodos, 76,8\% das famílias com acidentes e $83,1 \%$ das sem acidentes moravam em casas de um e 2 cômodos. Apenas 7,1\% das famílias com acidentes e 3,0\% das sem acidentes moravam em casas de 4 cômodos ou mais. O número médio de cômodos por domicílio foi, respectivamente, de 1,9 e 1,7. A gran- 
TABELA 8

Incidência de acidentes segundo idade e sexo das crianças no período de 1982 - 1984

\begin{tabular}{|c|c|c|c|c|c|}
\hline \multirow{2}{*}{$\begin{array}{l}\text { Grupo } \\
\text { Etário }\end{array}$} & \multirow{2}{*}{ Sexo } & \multirow{2}{*}{$\begin{array}{l}\text { No de } \\
\text { Crianças }\end{array}$} & \multirow{2}{*}{$\begin{array}{c}\text { No de } \\
\text { Acidentes }\end{array}$} & \multicolumn{2}{|c|}{ Acidentes/Ano } \\
\hline & & & & No & $\%$ \\
\hline 1 ano & $\begin{array}{l}M \\
F\end{array}$ & $\begin{array}{l}115 \\
100\end{array}$ & 1 & $\begin{array}{l}0,5 \\
-\end{array}$ & 0,43 \\
\hline 1 e 2 anos & $\begin{array}{l}\mathrm{M} \\
\mathrm{F}\end{array}$ & $\begin{array}{r}100 \\
89\end{array}$ & $\begin{array}{l}15 \\
12\end{array}$ & $\begin{array}{l}7,5 \\
6,0\end{array}$ & $\begin{array}{l}7,50 \\
6,74\end{array}$ \\
\hline 3 e 4 anos & $\begin{array}{l}\mathrm{M} \\
\mathrm{F}\end{array}$ & $\begin{array}{l}96 \\
86\end{array}$ & $\begin{array}{l}16 \\
12\end{array}$ & $\begin{array}{l}8,0 \\
6,0\end{array}$ & $\begin{array}{l}8,33 \\
6,98\end{array}$ \\
\hline 5 a 9 anos & $\begin{array}{l}\mathrm{M} \\
\mathrm{F}\end{array}$ & $\begin{array}{l}147 \\
183\end{array}$ & $\begin{array}{l}33 \\
17\end{array}$ & $\begin{array}{r}16,5 \\
8,5\end{array}$ & $\begin{array}{r}11,22 \\
4,64\end{array}$ \\
\hline 10 a 12 anos & $\begin{array}{l}\mathrm{M} \\
\mathrm{F}\end{array}$ & $\begin{array}{l}51 \\
69 \\
\end{array}$ & $\begin{array}{r}10 \\
6 \\
\end{array}$ & $\begin{array}{l}5,0 \\
3,0 \\
\end{array}$ & $\begin{array}{l}9,80 \\
4,35 \\
\end{array}$ \\
\hline Total & & 1036 & 122 & 61,0 & 5,89 \\
\hline
\end{tabular}

TABELA 9

Local de ocorrência de acidentes de crianças segundo sexo e faixa etária, no período de 1982 - $1984^{*}$

\begin{tabular}{|c|c|c|c|c|c|c|c|}
\hline \multirow{3}{*}{$\begin{array}{l}\text { Local } \\
\text { de Sexo } \\
\text { ocorrência }\end{array}$} & \multicolumn{6}{|c|}{ Faixa etária } & \multirow[b]{3}{*}{$\begin{array}{l}\text { Total Geral } \\
\text { № } \quad \% \%\end{array}$} \\
\hline & \multicolumn{2}{|c|}{0 a 4 anos } & \multicolumn{2}{|c|}{5 anos mais } & \multicolumn{2}{|c|}{ Total } & \\
\hline & Fem. & Masc. & Fem. & Masc. & Fem. & Masc. & \\
\hline $\begin{array}{l}\text { Área externa } \\
\text { da casa }\end{array}$ & $\begin{array}{c}10 \quad 20,4 \\
(41,7)\end{array}$ & $12 \underset{(37,5)}{24,5}$ & $\begin{array}{c}10 \quad 20,4 \\
(43,5)\end{array}$ & ${ }_{(39,5)}^{34,7}$ & $\begin{array}{c}20 \quad 40,8 \\
(42,6)\end{array}$ & $\begin{array}{c}29{ }_{(38,7)}^{59,2} \\
{ }^{2}\end{array}$ & $\begin{array}{c}49 \quad 100,0 \\
(40,1)\end{array}$ \\
\hline Quarto & $\begin{array}{l}5 \quad 29,4 \\
(20,8)\end{array}$ & $\begin{array}{l}5 \quad 35,3 \\
(18,7)\end{array}$ & ${ }^{4} \underset{(17,4)}{23,5}$ & $2_{(4,7)}^{11,8}$ & $\begin{array}{l}9 \quad 52,9 \\
(19,2)\end{array}$ & ${ }_{(10,7)}^{47,1}$ & $\begin{array}{c}17 \quad 100,0 \\
(13,9)\end{array}$ \\
\hline Escada & - & $\begin{array}{l}2 \underset{(6,3)}{40,0} \\
{ }^{2}\end{array}$ & $\begin{array}{l}2 \quad 40,0 \\
(8,7)\end{array}$ & ${ }^{1}{ }_{(2,3)}^{20,0}$ & $\begin{array}{l}240,0 \\
(4,3)\end{array}$ & $\begin{array}{l}3 \quad 60,0 \\
(4,0)^{6}\end{array}$ & $\begin{array}{l}5 \quad 100,0 \\
(4,1)\end{array}$ \\
\hline Cozinha & $4_{(16,7)}^{44,4}$ & $\begin{array}{l}5 \quad 55,6 \\
(15,6)\end{array}$ & - & - & $\begin{array}{l}4 \quad 44,4 \\
(8,5)\end{array}$ & ${ }^{5}(6,6)^{55,6}$ & $\begin{array}{l}9 \quad 100,0 \\
(7,4)\end{array}$ \\
\hline Via Pública & ${ }^{4}{ }_{(16,7)}^{13,8}$ & ${ }^{4}{ }_{(12,5)}^{13,8}$ & $\left.{ }^{3}(13,0)\right)^{10,3}$ & $\left.{ }_{(41,8)}^{18}\right)^{62,1}$ & $\begin{array}{l}7 \quad 24,1 \\
(14,7)\end{array}$ & ${ }_{(29,3)}^{75,9}$ & $29 \quad 100,0$ \\
\hline Escola & - & - & $\begin{array}{l}2 \underset{(8,7)}{50,0} \\
{ }^{2}\end{array}$ & $2 \underset{(4,7)^{50,0}}{ }$ & $\begin{array}{l}2 \underset{(4,3)}{50,0} \\
.\end{array}$ & $2 \underset{(2,7)^{50,0}}{ }$ & $\begin{array}{l}4 \underset{(3,3)}{100,0} \\
.\end{array}$ \\
\hline Rio/Piscina & - & - & - & $2 \underset{(4,7)}{100,0}$ & - & $\begin{array}{l}2 \underset{(2,7)}{100,0} \\
-{ }^{2}\end{array}$ & $2 \underset{(1,7)}{100,0}$ \\
\hline Outros & $\begin{array}{l}1{ }^{14,1)} \\
14,3\end{array}$ & $\begin{array}{c}3 \quad 42,8 \\
(9,4)\end{array}$ & $\begin{array}{l}28,6 \\
(8,7)\end{array}$ & ${ }^{1}{ }_{(2,3)}^{14,3}$ & $\begin{array}{l}3 \quad 42,9 \\
(6,4)\end{array}$ & $4{ }_{(5,3)}^{57,1}$ & $\begin{array}{l}7 \quad 100,0 \\
(5,7)\end{array}$ \\
\hline Total & $\begin{array}{c}24 \quad 19,7 \\
(100,0)\end{array}$ & $\begin{array}{c}32 \quad 26,2 \\
(100,0)\end{array}$ & $\begin{array}{c}23 \quad 18,9 \\
(100,0) \\
\end{array}$ & $\begin{array}{c}43 \quad 35,2 \\
(100,0)\end{array}$ & $\begin{array}{cc}47 \quad 38,5 \\
(100,0) \\
\end{array}$ & $\begin{array}{c}75 \quad 61,5 \\
(100,0) \\
\end{array}$ & $\begin{array}{c}122 \quad 100,0 \\
(100,0)\end{array}$ \\
\hline
\end{tabular}

* Os números entre parênteses referem-se às percentagens nas colunas.

de maioria das casas era de alvenaria $(87,9 \%$ e $81,0 \%)$. A presença de escadas em domicílio ocorreu em $38,4 \%$ das casas de famílias com acidentes e $37,8 \%$ das sem acidentes.

Das famílias estudadas, 99,0\% das com acidentes e $98,6 \%$ das sem acidentes utilizavam gás de botijão para cozinhar.

As casas eram abastecidas de água encanada da rede pública em cerca de $90 \%$ do total. No entanto, ainda
6,1\% das famílias com acidentes e 7,6\% das famílias sem acidentes usavam água de poço.

Das 99 famílias com acidentes, apenas uma morava em apartamento o que não ocorreu em nenhuma das famílias sem acidentes.

No que tange ao estudo descritivo dos acidentes relatados nas entrevistas, verificou-se que das 99 famílias que referiram acidentes, em 83 foi relatado apenas um acidente; em 10 famílias ocorreram 2 acidentes; em 5 
TABELA 10

Natureza de lesão em crianças acidentadas, segundo sexo e faixa etária, no período de 1982 - 1984*

\begin{tabular}{|c|c|c|c|c|c|c|c|}
\hline \multirow{3}{*}{ Lesão } & \multicolumn{6}{|c|}{ Faixa etária } & \multirow[b]{3}{*}{$\begin{array}{l}\text { Total Geral } \\
\text { ㅇ. } \%\end{array}$} \\
\hline & \multicolumn{2}{|c|}{0 a 4 anos } & \multicolumn{2}{|c|}{5 anos mais } & \multicolumn{2}{|c|}{ Total } & \\
\hline & 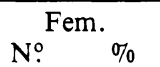 & $\begin{array}{l}\text { Masc. } \\
\text { No. } \%\end{array}$ & No ${ }^{2}{ }^{2} \%$ & \begin{tabular}{l}
\multicolumn{2}{c}{ Masc. } \\
No. $\%$
\end{tabular} & \begin{tabular}{l}
\multicolumn{2}{c}{ Fem. } \\
No
\end{tabular} & \begin{tabular}{l}
\multicolumn{2}{c}{ Masc. } \\
No. $\%$
\end{tabular} & \\
\hline Contusão & $\begin{array}{c}5 \quad 16,7 \\
(20,8)\end{array}$ & $\begin{array}{l}9 \quad 30,0 \\
(28,2)\end{array}$ & $\begin{array}{l}9 \quad 30,0 \\
(39,1)\end{array}$ & $\begin{array}{l}7_{(16,3)}^{23,3} \\
\end{array}$ & $\begin{array}{cc}14 & 46,7 \\
(29,8)\end{array}$ & $\left.{ }_{(21,3)}\right)^{53,3}$ & $\begin{array}{c}30 \quad 100,0 \\
(24,6)\end{array}$ \\
\hline Corte & $\begin{array}{l}7 \underset{(29,2)}{21,9} \\
\end{array}$ & ${ }_{(25,0)}^{825,0}$ & $4 \underset{(17,4)}{12,5}$ & ${ }_{(30,2)}^{40,6}$ & ${ }^{11} \underset{(23,4)}{34,4}$ & $21_{(28,0)}^{65,6}$ & $32 \quad 100,0$ \\
\hline Escoriação & $\begin{array}{l}3 \quad 14,3 \\
(12,5)\end{array}$ & $4_{(12,5)} 19,0$ & $\begin{array}{l}5 \quad 23,8 \\
(21,8)\end{array}$ & $\begin{array}{l}9{ }_{(20,9)}^{42,9} \\
\text { (2) }\end{array}$ & $\begin{array}{lr}8 & 38,1 \\
(17,0)\end{array}$ & $13 \underset{(17,3)}{61,9}$ & $21 \underset{(17,2)}{100,0}$ \\
\hline Laceração & $1_{(4,2)}^{7,7}$ & $\begin{array}{l}3{ }_{(9,4)}^{23,1} \\
{ }^{2}\end{array}$ & 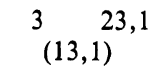 & $\begin{array}{l}6{ }_{(14,0)}^{46,1} \\
\text {. }\end{array}$ & $4{ }_{(8,5)}^{30,8}$ & ${ }^{9}{ }_{(12,0)}^{69,2}$ & $\begin{array}{c}13 . \quad 100,0 \\
(10,6)\end{array}$ \\
\hline Queimadura & $\begin{array}{c}3{ }_{(12,5)}^{37,5} \\
\text {. }\end{array}$ & ${ }_{(12,5)}^{50,0}$ & - & ${ }^{1}{ }_{(2,3)}^{12,5}$ & $\begin{array}{l}37,5 \\
(6,4)\end{array}$ & $5{ }_{(6,7)^{62,5}}^{62}$ & $\begin{array}{l}8 \quad 100,0 \\
(6,6)\end{array}$ \\
\hline $\begin{array}{l}\text { Fratura } \\
\text { Luxações }\end{array}$ & $\begin{array}{l}5 \quad 35,7 \\
(20,8)\end{array}$ & $\begin{array}{l}2{ }_{(6,2)}^{14,3} \\
\end{array}$ & $1_{(4,3)^{7,1}}^{7,1}$ & $\begin{array}{l}642,9 \\
(14,0)\end{array}$ & $\begin{array}{c}6 \quad 42,9 \\
(12,8)\end{array}$ & $\begin{array}{l}8 \quad 57,1 \\
(10,7)\end{array}$ & $\begin{array}{c}14 \quad 100,0 \\
(11,5)\end{array}$ \\
\hline Afogamento & - & - & - & $\begin{array}{l}1100,0 \\
(2,3)\end{array}$ & - & $\begin{array}{l}1100,0 \\
(1,3)\end{array}$ & $\begin{array}{l}1100,0 \\
(0,9)\end{array}$ \\
\hline Outras & - & $2 \underset{(6,2)}{66,7}$ & $\begin{array}{l}1 \underset{(4,3)}{33,3} \\
{ }^{3}\end{array}$ & - & $\begin{array}{l}1{ }_{(2,1)}^{33,3} \\
\end{array}$ & $2{ }_{(2,7)^{66,7}}^{66}$ & $\begin{array}{l}3{ }_{(2,4)}^{100,0} \\
\end{array}$ \\
\hline Total & $\begin{array}{c}24 \quad 19,7 \\
(100,0)\end{array}$ & $\begin{array}{c}32 \quad 26,2 \\
(100,0)\end{array}$ & $\begin{array}{c}23 \quad 18,9 \\
(100,0)\end{array}$ & $\begin{array}{c}43 \quad 35,2 \\
(100,0)\end{array}$ & $\begin{array}{c}47 \quad 38,5 \\
(100,0)\end{array}$ & $\begin{array}{c}75 \quad 61,5 \\
(100,0)\end{array}$ & $\begin{array}{c}122 \quad 100,0 \\
(100,0)\end{array}$ \\
\hline
\end{tabular}

* Os números entre parênteses referem-se às percentagens nas colunas.

famílias foram mencionados 3 e uma família registrou 4 acidentes no período em estudo.

A Tabela 8 mostrou os acidentes relatados e as crianças das famílias estudadas segundo idade e sexo. Verificou-se, assim, que, para o total de 1.036 crianças menores de 12 anos foram relatados, no período de 2 anos considerados, 122 acidentes, o que significou uma incidência de 5,89 acidentes por 100 crianças por ano.

Verificou-se também que a incidência de acidentes foi quase nula em menores de um ano (apenas um acidente entre 215 crianças). À medida em que aumentou a idade das crianças houve um aumento da incidência de acidentes, em meninos de 5 a 9 anos atingindo um pico de 11,22 acidentes/100 crianças/ano.

Já em relação às meninas, a incidência foi sempre menor e o pico verificou-se na faixa de 3 e 4 anos; na faixa de 5 a 9 anos houve 2,4 vezes mais acidentes em meninos do que em meninas, semelhante ao que se verificou na faixa de 10 a 12 anos (2,2 vezes mais em meninos).

É preciso, porém, considerar o fato de que a incidência aqui verificada em menores de 2 anos está subestimada, uma vez que não se levou em conta o fato de que as crianças dessa faixa não estiveram expostas a acidentes pelo mesmo período que as maiores de 2 anos. Esse fato será considerado ao medir-se a mortalidade por acidentes. Ainda assim, o fato primordial é que ocorreram muito poucos acidentes em crianças de baixa idade na amostra em estudo, como mostrou a Tabela 8.
Ao estudar o local de ocorrência, bem como outras características dos acidentes, optou-se por subdividir as crianças, com base nas próprias incidências por idade, em um subgrupo de crianças de 0 a 4 anos e outro de crianças de 5 anos e mais. Além disso, considerou-se o fato de que, na população em tela, para a grande maioria dos menores de 5 anos, o ambiente em que vivem a maior parte do tempo é o domicílio (e áreas adjacentes), ao passo que para crianças maiores já a escola e outros locais são cada vez mais freqüentados.

A Tabela 9 relaciona os acidentes quanto ao local de ocorrência, faixa etária e sexo das crianças.

Mais de $60 \%$ dos acidentes ocorreram na área externa dos domicílios $(40,2 \%)$ ou em vias públicas $(23,8 \%)$; ainda outros $13,9 \%$ dos acidentes ocorreram no quarto.

A Tabela 9 também mostrou que os acidentes ocorridos fora do domicílio (via pública, escola, rios/piscinas ou outros locais) foram mais freqüentes em meninos de 5 anos e mais $-62,1 \%$ do total de acidentes na via pública, por exemplo, ao passo que meninas de 5 anos e mais, nesse aspecto, apresentaram proporção de acidentes na via pública semelhante à de meninas menores de 5 anos.

Os acidentes na área externa do domicílio distribuiram-se de maneira mais uniforme, sendo também mais freqüentes dentre eles, os ocorridos em meninos de 5 anos e mais.

Já os acidentes na cozinha ocorreram apenas em 
TABELA 11

Local do corpo atingido de crianças acidentadas, segundo sexo e faixa etária, no período de 1982 - 1984*

\begin{tabular}{|c|c|c|c|c|c|c|c|c|c|c|c|c|}
\hline & \multicolumn{11}{|c|}{ Faixa etária } & \multirow[b]{3}{*}{ Total Geral } \\
\hline \multirow{3}{*}{$\begin{array}{l}\text { Local Sexo } \\
\text { atingido }\end{array}$} & \multicolumn{4}{|c|}{0 a 4 anos } & \multicolumn{4}{|c|}{5 anos mais } & \multicolumn{3}{|c|}{ Total } & \\
\hline & \multicolumn{2}{|c|}{ Fem. } & \multicolumn{2}{|c|}{ Masc. } & \multicolumn{2}{|c|}{ Fem. } & \multicolumn{2}{|c|}{ Masc. } & \multicolumn{2}{|c|}{ Fem. } & Masc. & \\
\hline & № & $\%$ & No & $\%$ & No & $\%$ & No & $\%$ & No & $\%$ & No $\quad \%$ & N. $\quad \%$ \\
\hline \multirow[t]{2}{*}{ Cabeça } & & 32,5 & \multirow{2}{*}{\multicolumn{2}{|c|}{$(34,4)$}} & \multirow{2}{*}{\multicolumn{2}{|c|}{$\begin{array}{l}7{ }_{(30,5)}^{17,5} \\
\text { (30, }\end{array}$}} & \multirow{2}{*}{\multicolumn{2}{|c|}{${ }^{9}(20,9)^{22,5}$}} & \multirow{2}{*}{\multicolumn{2}{|c|}{$\begin{array}{c}20 \quad 50,0 \\
(42,5)\end{array}$}} & \multirow{2}{*}{${ }^{20}(26,6) 50,0$} & \multirow{2}{*}{$\begin{array}{c}40 \quad 100,0 \\
(32,8)\end{array}$} \\
\hline & \multicolumn{2}{|c|}{$(54,2)$} & & & & & & & & & & \\
\hline Tronco & \multicolumn{2}{|l|}{ - } & \multicolumn{2}{|c|}{$\begin{array}{l}3 \underset{(9,4)}{50,0} \\
.\end{array}$} & \multicolumn{2}{|c|}{$\begin{array}{l}2 \quad 33,3 \\
(8,7)\end{array}$} & \multicolumn{2}{|c|}{${ }^{1}{ }_{(2,3)}^{16,7}$} & \multicolumn{2}{|c|}{$\begin{array}{l}2 \quad 33,3 \\
(4,3)\end{array}$} & $4_{(5,3)}^{66,7}$ & $\begin{array}{l}6 \underset{(4,9)}{100,0} \\
{ }^{2}\end{array}$ \\
\hline Membros & \multirow{2}{*}{\multicolumn{2}{|c|}{$\begin{array}{l}5 \quad 19,2 \\
(20,8)\end{array}$}} & \multirow{2}{*}{\multicolumn{2}{|c|}{$\begin{array}{l}8 \underset{(25,0)}{30,8} \\
\text { (2) }\end{array}$}} & \multirow{2}{*}{\multicolumn{2}{|c|}{$4_{(12,4)}^{15,4}$}} & \multirow{2}{*}{\multicolumn{2}{|c|}{$\begin{array}{l}9{ }_{(20,9)}^{34,6} \\
\text { (1) }\end{array}$}} & \multirow{2}{*}{\multicolumn{2}{|c|}{$\begin{array}{c}934,6 \\
(19,1)\end{array}$}} & \multirow{2}{*}{${ }_{(27,7)}^{65,4}$} & $26 \quad 100,0$ \\
\hline superiores & & & & & & & & & & & & $(21,3)$ \\
\hline Membros & & 13,9 & & 11,1 & & 22,2 & & 52,8 & & 36,1 & 63,9 & $36 \quad 100,0$ \\
\hline Inferiores & & & & & & & & & & & $(30,7)$ & $(29,5)$ \\
\hline Diversas & 1 & 10,0 & & 40,0 & 1 & 10,0 & 4 & 40,0 & & 20,0 & $8 \quad 80,0$ & $10 \quad 100,0$ \\
\hline áreas & & & & & & & & & & & $(10,7)$ & $(8,2)$ \\
\hline Sem local & - & & & 66,7 & 1 & 33,3 & - & & & 33,3 & 66,7 & 3100,0 \\
\hline Definido & & & & & & & & & & & $(2,7)$ & $(2,5)$ \\
\hline Não se aplica & - & & - & & - & & 1 & $\begin{array}{l}100,0 \\
\text { 3) }\end{array}$ & - & & $\begin{array}{ll}1 & 100,0 \\
(1,3) & \end{array}$ & $1 \quad \begin{array}{l}100,0 \\
(0,8)\end{array}$ \\
\hline Total & 24 & 19,7 & 32 & 26,2 & 23 & 18,9 & & 35,2 & 47 & & $75 \quad 61,5$ & $122 \quad 100,0$ \\
\hline & & & & & & & & & & & $(100,0)$ & $(100,0)$ \\
\hline
\end{tabular}

* Os números entre parênteses referem-se às percentagens nas colunas.

crianças menores de 5 anos; também houve um predomínio de crianças menores de 5 anos dentre os acidentes ocorridos no quarto.

Como seria de esperar, os acidentes na escola ocorreram apenas em crianças de 5 anos e mais, bem como os acidentes em rio e piscina.

Quanto à natureza da lesão (Tabela 10), as lesões mais freqüentes foram cortes $(26,2 \%)$, contusões $(24,6 \%)$ e escoriações $(17,2 \%)$, vindo a seguir fraturas e luxações $(11,5 \%)$ e lacerações $(10,7 \%)$. As queimaduras foram relatadas apenas em $6,6 \%$ do total de acidentes.

Quase $90 \%$ das queimaduras ocorreram em menores de 5 anos. Grande parte dos cortes, escoriações, lacerações, fraturas e luxações ocorreram em meninos de 5 anos e mais.

Houve apenas um caso de afogamento (aliás, o único óbito do estudo), que também ocorreu em menino de 5 anos e mais.

Já no que diz respeito ao local do corpo atingido, a Tabela 11 mostrou que em $32,9 \%$ dos casos, o local atingido foi a cabeça, seguindo-se os membros inferiores $(29,5 \%)$ e os membros superiores $(21,8 \%)$. Em alguns casos houve acometimento de várias regiões.

Para as crianças menores de 5 anos, a cabeça foi o local mais freqüentemente atingido $(54,2 \%$ das meninas e $34,5 \%$ dos meninos), ao passo que apenas em $20,8 \%$ das vezes, para as meninas, e $12,5 \%$ para os me- ninos, o local atingido foram os membros inferiores. Já no caso das crianças de 5 anos e mais, os membros inferiores foram o local mais atingido em 44,2\% dos meninos e $34,8 \%$ das meninas.

Quanto ao tipo de acidentes, 54,1\% do total foram quedas, vindo a seguir ferimentos com objetos cortantes ou penetrantes $(13,1 \%)$, modeduras de animais $(9,9 \%)$, acidentes de trânsito $(7,4 \%)$, e queimaduras $(6,6 \%)$ (Tabela 12).

As quedas distrubuíram-se de maneira muito semelhante segundo sexo e faixa etária.

Ao se analisar a proporção que as quedas representaram do total de acidentes em cada subgrupo, a Tabela 12 mostrou que quase $70 \%$ dos acidentes verificados em meninas foram quedas, ao passo que para meninos foi de apenas $45,4 \%$. Esse comportamento foi semelhante para menores de 5 e para crianças de 5 anos e mais.

No que diz respeito aos ferimentos com objetos contundentes ou penetrantes, quase $2 / 3$ ocorreram em meninos de 5 anos e mais. Esses acidentes representaram parcela considerável dos acidentes ocorridos no subgrupo de meninos de 5 anos e mais.

Dois terços dos casos de mordeduras de animais, bem como dos acidentes de trânsito, ocorreram em meninos.

Todos os casos de impacto acidental contra objetos ou pessoas ocorreram com meninos; por tudo isso é que as quedas acabaram representando menor proporção dos 
TABELA 12

Tipo de acidente ocorrido com crianças, segundo sexo e faixa etária, no período de 1982 - 1984.

\begin{tabular}{|c|c|c|c|c|c|c|c|}
\hline \multirow{4}{*}{$\begin{array}{l}\text { Tipo de } \\
\text { Acidente }\end{array}$} & \multicolumn{7}{|c|}{ Faixa etária } \\
\hline & \multicolumn{2}{|c|}{0 a 4 anos } & \multicolumn{2}{|c|}{5 anos mais } & \multicolumn{2}{|c|}{ Total } & \multirow[t]{2}{*}{ Total geral } \\
\hline & Fem. & Masc & .Fem. & Masc. & Fem. & Masc. & \\
\hline & N. & No & No & No & No & No & № \\
\hline Quedas & $\begin{array}{c}1725,8 \\
(70,8)\end{array}$ & $\begin{array}{l}17 \underset{(53,1)}{25,8} \\
\end{array}$ & $\begin{array}{l}15 \underset{(65,2)}{22,7} \\
\end{array}$ & 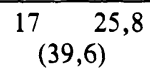 & $\begin{array}{l}3248,5 \\
(68,1)\end{array}$ & $34 \underset{(45,4)}{51,5}$ & $\begin{array}{c}66100,0 \\
(54,1)\end{array}$ \\
\hline $\begin{array}{l}\text { Ferimento com objetos cortantes } \\
\text { ou penetrantes }\end{array}$ & $2_{(8,3)}^{12,5}$ & $\begin{array}{l}3 \\
(9,4)\end{array}$ & $1_{(4,4)}^{6,3}$ & $\begin{array}{l}10 \quad 62,5 \\
(23,3)\end{array}$ & ${ }^{3}(6,4)^{18,7}$ & $\begin{array}{c}13 \quad 81,3 \\
(17,3)\end{array}$ & $\begin{array}{c}16 \quad 100,0 \\
(13,1)\end{array}$ \\
\hline Mordedura animal & $1_{(4,2)}^{8,3}$ & $\begin{array}{l}3 \\
(9,4)\end{array}$ & $\begin{array}{l}3225,0 \\
(13,0)\end{array}$ & $\begin{array}{l}5_{(11,6)}^{41,7} \\
\end{array}$ & $4_{(8,5)}^{33,3}$ & $\begin{array}{l}8 \quad 66,7 \\
(10,7)\end{array}$ & 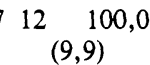 \\
\hline Acidente de trânsito & - & $1_{(3,1)}^{11,1}$ & ${ }^{2} 33,3$ & $\begin{array}{l}5 \quad 55,6 \\
(11,6)\end{array}$ & ${ }^{3}(6,4)^{33,3}$ & $\begin{array}{l}6 \\
(8,0)\end{array}$ & $\begin{array}{l}9100,0 \\
(7,4)\end{array}$ \\
\hline $\begin{array}{l}\text { Queimaduras com substâncias } \\
\text { quentes }\end{array}$ & $\begin{array}{l}3 \\
(12,5)\end{array}$ & $\begin{array}{l}450,0 \\
(12,5)\end{array}$ & - & $1_{(2,3)}^{12,5}$ & $\begin{array}{l}3{ }^{3} 37,5 \\
(6,4)\end{array}$ & $\begin{array}{c}5 \\
(6,7)\end{array}$ & $\begin{array}{l}8100,0 \\
(6,6)\end{array}$ \\
\hline $\begin{array}{l}\text { Impacto acidental contra objetos } \\
\text { ou pessoas }\end{array}$ & - & $2_{(6,3)}^{40,0}$ & - & $\begin{array}{l}3 \quad 60,0 \\
(7,0)\end{array}$ & - & $\begin{array}{l}5 \quad 100,0 \\
(6,7)\end{array}$ & $\begin{array}{l}5100,0 \\
(4,1)\end{array}$ \\
\hline $\begin{array}{l}\text { Aspiração de objetos com } \\
\text { sufocação }\end{array}$ & - & ${ }^{1}(3,1)^{10,0}$ & - & 一 & - & $\begin{array}{l}1100,0 \\
(1,3)\end{array}$ & $\begin{array}{l}1100,0 \\
(0,8)\end{array}$ \\
\hline Afogamento & 一 & - & - & $\begin{array}{l}1100,0 \\
(2,3)\end{array}$ & - & $\begin{array}{l}1100,0 \\
(1,3)\end{array}$ & $1_{(0,8)}^{100,0}$ \\
\hline $\begin{array}{l}\text { Penetração de corpo estranho } \\
\text { no olho }\end{array}$ & - & 一 & - & $\begin{array}{l}1100,0 \\
(2,3)\end{array}$ & - & $\begin{array}{l}100,0 \\
(1,3)\end{array}$ & $\begin{array}{l}1100,0 \\
(0,8)\end{array}$ \\
\hline Aprisionamento entre objetos & - & - & ${ }^{1} \underset{(4,4)}{100,0}$ & - & $\begin{array}{l}100,0 \\
(2,1)\end{array}$ & - & $\begin{array}{l}1100,0 \\
(0,8)\end{array}$ \\
\hline Síndrome da criança espancada & $\begin{array}{l}1100,0 \\
(4,2)\end{array}$ & - & - & - & $\begin{array}{l}100,0 \\
(2,1)\end{array}$ & - & $\begin{array}{l}1100,0 \\
(0,8)\end{array}$ \\
\hline Circustâncias desconhecidas & - & $\begin{array}{l}1{ }^{100,0} \\
(3,1)\end{array}$ & - & - & 一 & $\begin{array}{l}1100,0 \\
(1,3)\end{array}$ & $\begin{array}{l}1100,0 \\
(0,8)\end{array}$ \\
\hline Total & $\begin{array}{c}24 \quad 19,7 \\
(100,0)\end{array}$ & $\begin{array}{c}32 \quad 26,2 \\
(100,0)\end{array}$ & $\begin{array}{c}23 \quad 18,9 \\
(100,0)\end{array}$ & $\begin{array}{l}43 \quad 35,2 \\
(100,0)\end{array}$ & $\begin{array}{l}47 \quad 38,5 \\
(100,0)\end{array}$ & $\begin{array}{l}75 \quad 61,5 \\
(100,0)\end{array}$ & $\begin{array}{l}122100,0 \\
(100,0)\end{array}$ \\
\hline
\end{tabular}

* Os números entre parenteses referem-se a percentagens nas colunas.

acidentes dos meninos.

O único caso registrado como síndrome da criança espancada verificou-se numa menina menor de 5 anos.

Houve um acidente registrado em circunstâncias desconhecidas - ocorreu na creche, na ausência da mãe.

Com relação ao local onde receberam tratamento, $57,5 \%$ dos casos foram atendidos em hospital ou pronto socorro, na grande maioria do sistema público ou previdenciário. Em $33,6 \%$ dos casos o tratamento foi feito em casa ou na farmácia, sendo o Posto de Saúde referido em apenas $4,9 \%$ dos casos.

Não houve necessidade de internação na grande maioria dos casos $(91,0 \%)$. Quando necessária, a internação foi de um dia em 3 casos, havendo 2 casos com necessidade de internação de 6 a 9 dias e 2 casos com necessidade de 20 dias ou mais.

O tempo necessário para recuperação referido mostra que em 32,0\% dos casos foram necessários 15 dias ou mais para que a recuperação se desse, sendo que em

* Obrigações Reajustáveis do Tesouro Nacional apenas $11,5 \%$ dos casos se relata um tempo inferior a um dia para a recuperação.

Em $69,7 \%$ dos casos foram necessários 3 dias ou mais para a recuperação.

A recuperação foi total em $88,5 \%$ dos casos. Contudo, ocorreram 12 casos ( $9,8 \%$ do total) com recuperação parcial, com sinais; houve um caso de recuperação parcial com limitações, e ocorreu ainda um óbito.

Em relação à gravidade do acidente, na opinião dos entrevistados, $49(40,2 \%)$ deles foram considerados graves.

Finalmente, quanto ao dinheiro dispendido para o tratamento das crianças acidentadas, em 41 casos as pessoas entrevistadas $(33,6 \%)$ referiram nada ter gastado; $44(36,1 \%)$ gastaram menos de 1 ORTN*; $8(6,6 \%)$ gastaram de 1 a 2 ORTNs; $11(7,4 \%)$ gastaram 3 ORTNs ou mais. Dezoito entrevistados não souberam informar o valor do gasto.

Ao serem inquiridas sobre com que fatores associaram o acidente, $47(38,5 \%)$ das entrevistas referiram esportes, brincadeiras e jogos infantis; $23(18,9 \%)$ relacio- 
naram os acidentes a aspectos da construção das casas; $9 \%$ dos casos foram relacionados à presença de animais; foram relacionados, menos freqüentemente, com veículos, utensílios de cozinha, móveis, líquidos corrosivos e inflamáveis, plantas e árvores. Algumas pessoas não souberam relacionar os acidentes a quaisquer fatores.

Das pessoas entrevistadas, $89(73 \%)$ referiram que o acidente poderia ter sido evitado, ao passo que 32 $(26,2 \%)$ julgaram o acidente inevitável. Uma pessoa disse ignorar se poderia ter sido evitado, por desconhecer as circustâncias em que ocorreu.

Quanto à responsabilidade pelo acidente, em 33 casos as pessoas não atribuíram responsabilidade, por terem julgado o acidente inevitável; outras 5 pessoas não sabiam de quem era a responsabilidade.

Das 84 entrevistas que atribuíram responsabilidade pelos acidentes, $34(40,5 \%)$ atribuiram-na à mãe da criança, $31(36,9 \%)$ à própria criança, $13(15,5 \%)$ a outras pessoas; apenas 5 atribuíram a responsabilidade a algum objeto e somente uma responsabilizou condições de construção.

Procurou-se, a seguir, verificar com quem estava a criança no momento em que ocorreu o acidente. Apesar de, como foi visto, quase $80 \%$ das crianças serem cuidadas pela mãe, em $62,3 \%$ dos acidentes, as crianças se encontravam sozinhas ou com outra criança e apenas $19,7 \%$ estavam com a mãe.

Finalmente, procurou-se construir coeficientes de mortalidade e letalidade por acidente. $\mathrm{O}$ coeficiente de mortalidade obtido foi de 114,9 óbitos para 100.000 crianças menores de 12 anos por ano. Quanto à letalidade, dos 122 acidentes referidos, apenas um resultou em óbito.

Assim, mesmo ressaltando os problemas daí decorrentes quanto à representatividade, a letalidade foi de 8,2 óbitos por mil acidentes.

\section{DISCUSSÃO}

Os autores que se têm dedicado ao estudo dos acidentes na infância têm analisado aspectos relativos principalmente à mortalidade $9,10,13$ ou aos casos em que houve necessidade de atendimento em serviços de emergência ${ }^{6,7,11,12}$. O fato de se circunscrever o estudo sobre acidentes na infância aos casos que chegam a ser atendidos em hospitais ou pronto-socorros, ou ainda aqueles que levam ao óbito, pode dificultar o reconhecimento correto da magnitude do problema bem como de suas características epidemiológicas. $\mathrm{O}$ presente estudo buscou conhecer as características de acidentes referidos pela família de crianças, quando em consulta de controle de saúde, em Postos de Assistência Médica. Se por um lado é importante reconhecer que num estudo retrospectivo como esse é passível de crítica, por se basear na memória dos entrevistados, por outro lado, vale ressaltar que quase $40 \%$ das crianças acidentadas incluídas neste estudo não chegaram a ser atendidas em hospitais ou pronto-socorros. Essa constatação sugere uma explicação para o fato de que a maioria dos acidentes aqui relatados fossem quedas, acidentes com objetos cortantes e penetrantes e mordeduras de animais, em contraposição às casuísticas hospitalares, estas mostram, como Dershewitz e Christophersen ${ }^{3}$ que a principal causa de óbito em acidentes na infância foi queimadura, seguida da asfixia mecânica e afogamento, ou como Koblenz ${ }^{7}$ que dá ênfase às fraturas $(47 \%)$ e queimaduras $(20 \%)$ como importantes causas de agravo nos acidentes na infância.

No presente trabalho as fraturas e luxações corresponderam a $11,5 \%$ do total e as queimaduras atingiram somente $6,6 \%$ do total, tendo prevalecido, como já referimos, os cortes e as contusões.

Outro aspecto que cabe ressaltar foi a grande semelhança encontrada na caracterização das famílias e domicílios das crianças acidentadas em relação às demais famílias, o que permite afirmar que o grupo populacional em que ocorreram acidentes, no período em estudo, era representativo da população estudada, população essa residente em bairros da periferia de uma cidade grande. Houve apenas diferenças quanto à idade dos pais e ao número e idade dos filhos o que, aliás, é perfeitamente explicável. Famílias mais numerosas, com maior número de filhos maiores de 2 anos, apresentam maior probabilidade de que venha a ocorrer algum tipo de acidente.

Com referência à incidência por idade, verificou-se um número muito reduzido de acidentes em menores de um ano, dado esse concordante com os referidos por Manciaux e Jeanneret ${ }^{8}$ e por Koblenz ${ }^{7}$. Verificou-se, também, incidência muito maior de acidentes em meninos de 5 a 9 anos, sendo registrado um número quase 3 vezes maior do que o verificado em meninas da mesma faixa etária. Para meninos de 10 a 12 anos houve mais do dobro de acidentes/criança/ano do que nas meninas da mesma idade. Esses dados são semelhantes aos referidos pela literatura $6,9,14$ e podem ser analisados, em parte, observando-se que os acidentes ocorridos fora do domicílio predominam em meninos maiores de 5 anos e pelo fato de que, em nosso meio, habitualmente as meninas brincam mais dentro do próprio domicílio, ao passo que os meninos desfrutam de maior liberdade, brincando fora do domicílio.

Essa característica de maior contato com o meio externo por parte dos meninos talvez seja, também, a explicação para o fato de $70 \%$ dos acidentes em meninas serem quedas, pela menor diversidade de exposição a riscos de acidentes, ao passo que $2 / 3$ dos mesmos foram ferimentos cortantes ou perfurantes, em meninos de 5 anos e mais. Reforça essa explicação o fato de que $2 / 3$ das mordeduras de animais e de acidentes de trânsito terem ocorrido com meninos.

Deve-se ressaltar, finalmente, que apesar de não ter sido constatada a necessidde de internação na grande maioria dos casos $(91,0 \%)$, em $32,0 \%$ do total de acidentes foram necessários 15 dias ou mais para a recuperação, o que implica grande ônus para o desempenho escolar dessas crianças, além dos cuidados especiais im- 
postos à família. Trouxe preocupação o fato de que em $11,5 \%$ dos casos a recuperação não foi total, persistindo sinais, ou limitações, ou ocorrendo, mesmo, o óbito (um caso). Considerou-se, assim, como de grande importância para a comunidade a elaboração de medidas que visem não somente reduzir o dano, mas também prevenir os acidentes, devendo tais medidas ser dirigidas à problemática que envolve cada realidade.

\section{CONCLUSÕES}

1. A não ser em relação ao número e idade dos filhos e idade dos pais, as características familiares (renda, ocupação, escolaridade dos pais, tempo de residência em São Paulo, procedência) e as de habitação (tipo de construção, número de cômodos, fornecimento de água, destino de dejetos, tipo de combustível usado para cozinhar) foram muito semelhantes entre as famílias de crianças que sofreram algum acidente no período em estudo, e as que não referiram acidentes em suas crianças.

2. Os acidentes mais freqüentes foram, pela ordem: quedas, ferimentos causados por objetos cortantes ou penetrantes e mordeduras de animais.

3. As lesões mais freqüentes foram cortes, contusões e escoriações.

4. Houve maior incidência de acidentes em meninos de 5 a 9 anos, vindo a seguir meninos de 10 a 12 anos. A incidência em meninas não mostrou aumento nas crianças de 5 anos ou mais.
5. A recuperação das crianças acidentadas foi total em $88,5 \%$ dos casos, tendo havido 12 casos com recuperação parcial com sinais, 1 caso de recuperação parcial com limitação e 1 óbito.

6. A incidência de acidentes em menores de um ano foi muito baixa, comparada à que se observou em outras idades aqui estudadas; a incidência de acidentes em meninos de 5 a 9 anos e de 10 a 12 anos foi o triplo e o dobro, respectivamente, daquela verificada em meninas das mesmas faixas etárias. A incidência total de acidentes na amostra estudada foi de 5,89 acidentes por 100 crianças por ano.

7. O coeficiente de mortalidade corrigido, calculado para o universo de crianças das famílias incluídas no estudo, foi de 114,9 óbitos para 100.000 crianças menores de 12 anos, por ano.

8. A letalidade foi de 8,2 óbitos por mil acidentes.

9. Estudar os acidentes com base em informação prestada pela família permitiu acrescentar uma série de dados epidemiológicos complementares aos passíveis de obter-se em estudos de causuísticas de mortalidade ou morbidade hospitalar.

\section{AGRADECIMENTOS}

Aos médicos Aldo Lelis Barbiere e Betty Beatriz Andrade, bem como aos funcionários dos Postos de Assistência Médica Jardim São Luiz e Maria Antonieta de Barros por sua colaboração na fase de coleta de dados; ao técnico Fernão Dias de Lima por sua colaboração na fase de tabulação e apuração dos dados.

UNGLERT, C.V. de S. et al. [Epidemiological characteristics of childhood accidents.] Rev. Saúde públ., S. Paulo, 21: 233-45, 1987.

ABSTRACT: The epidemiological characteristics of those accidents which had happened to children in the previous 2 years were studied by means of interviews with the families of children less than 12 years of age, who had been assisted in two Health Centres in an outlying area of S. Paulo City, Brazil. A total of 388 families were interviewed, with a total of 1036 children less than 12 years old. Of these families, 289 did not report any accident involving children during the previous 2 years, but 99 families reported at least one accident, and a total of 122 accidents were registered. The most frequent types of accidents were falls $(54.1 \%)$, wounds produced by cutting and piercing instruments of objects $(13.1 \%)$ and animal bites $(9.8 \%)$. The most frequent lesions were open wounds $(68 \%)$. The greatest incidence of accidents occurred in boys of 5 to 9 years old, followed by that in boys of 10 to 11 years of age. Recovery was complete in $88.5 \%$ of the cases, but there were $9.8 \%$ of cases (12) with partial recovery with scars, one case of partial, limited, recovery and one death. Only $9 \%$ of the cases needed hospitalization, but in $32 \%$ of the accidents 15 or more days were needed for recovery. The mortality rate in this study was 114.9 deaths per 100,000 children under 12 years of age per year, and the fatality rate was 8.2 deaths per thousand accidents. This study of accidents permitted the addition of complimentary data which favour a better epidemilogic charaterization characterization of accidents in children.

UNITERMS: Child. Accidents. Epidemiology. Mortality. Morbidity.

\section{REFERÊNCIAS BIBLIOGRÁFICAS}

1. BRANNICK, T. \& KIRKE, P. Childhood accidents in Ireland. J.Irish med. Ass., 73: 220-6, 1980.

2. CLARKE, A. \& WALTON, W.W. Effect of safety packa- ging on aspirin ingestion by children. Pediatrics, 63: 687-93, 1979.

3. DERSHEWITZ, R.A. \& CHRISTOPHERSEN, E.R. Child- 
hood household safety. Amer. J. Dis. Child., 138: 85-8, 1984.

4. FORTIN, J. Les accidents a' l' 'ecole maternelle. Etude epidemiologique et perspectives de prévention. Rev. Pediat., 20(1): 49-52, 1984.

5. GOUVEIA, A.J. Professores de amanhã: um estudo de escolha ocupacional. 2a ed. São Paulo, Livraria Pioneira, 1970.

6. HOZ, J.A.Q. \& HERNANDES, M.T. Estudio sobre algunas caracteristicas epidemiologicas y sociales de los accidentes en los niños y adolescentes. Rev. cub. Hig. Epid., 22: 3-12, 1984.

7. KOBLENZ, A. Acidentes a que estão sujeitas as crianças em casa e no seu meio ambiente. In: Seminário sobre Situação de Saúde nas Áreas Metropolitanas Brasileiras, São Paulo, 1975. Anais. São Paulo, Faculdade de Saúde Pública da USP, 1976. p. 54-65.

8. MANCIAUX, M. \& JEANNERET, O. Les accidents atteignant les enfants et les adolescents: de la conaissance épidémiologique à làction préventive. Rev. Epidem. Santé públ., 31: 433-44, 1983.

9. MELLO JORGE, M.H.P. Mortalidade por causas violentas no Município de São Paulo. São Paulo, 1979. [Tese de doutoramento - Faculdade de Saúde Pública da USP].
10. RODRIGUES, Y. et al. Estado atual dos acidentes na infância no Estado do Rio de Janeiro. J. Pediat., 59(1): 63-6, 1985.

11. SCHVARTSMAN, S. Plantas venenosas. São Paulo, Ed. Sarvier, 1979.

12. SCHVARTSMAN, S. Produtos químicos de uso domiciliar. São Paulo, Ed. Almed, 1980.

13. SIBERT, J.R. Children's accidents. Practitioner, 227: 205-8, 1983.

14. SIBERT, J.R. et al. Childhood accidents: an endemic of epidemic proportions. Arch. Dis. Child., 56: 225-34, 1981.

15. SPIEGEL, C.N. \& LINDAMAN, F.C. Children can't fly: a program to prevent childhood morbidity and mortality from window falls. Amer. J. publ. Hlth, 67: 1143-7, 1977.

16. WILSON, D. Contribuição para o conhecimento da medicina preventiva dos acidentes domésticos, estudo epidemiológico em um subdistrito do Município de São Paulo. São Paulo, 1966. [Tese de Cátedra - Faculdade de Medicina da USP].

Recebido para publicação em 18/12/1986 Aprovado para publicação em 27/4/1987 